Original Research

\title{
Concentric and Eccentric Force Changes with Elastic Band and Isotonic Heavy Resistance Training: A Randomized Controlled Trial
}

\author{
Eric Folkins ${ }^{1}$, Sidharth Sahni', John Ryann', Stacey Wooden ${ }^{3}$, Gina Bushby ${ }^{3}$, Christian Radzinski ${ }^{4}$ \\ 1 Department of Physical Therapy, Samson College, University of the Sciences, Philadelphia, PA, USA, 2 Department of Physical Therapy, Samson \\ College, University of the Sciences, Philadelphia, PA, USA; Better Home Care, Feasterville, PA, USA, ${ }^{3}$ Department of Physical Therapy, Samson College, \\ University of the Sciences, Philadelphia, PA, USA; Tender Touch Rehab Services, Lakewood Township, NJ, USA, ${ }^{4}$ Department of Physical Therapy, \\ Samson College, University of the Sciences, Philadelphia, PA, USA; Cora Physical Therapy, Lexington, SC, USA \\ Keywords: resistance training, movement system, shoulder, isokinetic, hip, elbow \\ https://doi.org/10.26603/001c.23672
}

\section{International Journal of Sports Physical Therapy}

Vol. 16, Issue 3, 2021

\begin{abstract}
Background
Inclusion of resistance training as part of a general fitness program to improve health, and lower risk of disease and injury is well established. Two common options to improve strength are elastic bands and weights. Comparison between elastic bands (as the sole resistance) to isotonic strengthening for concentric and eccentric strength outcomes following the use of low repetitions/heavy resistance has not been reported.
\end{abstract}

\section{Hypothesis/Purpose}

The purpose was to examine the effects of a four-week isotonic low repetitions/heavy resistance strengthening program compared to a low repetitions/heavy resistance elastic band strengthening program on shoulder external rotation, hip abduction, and elbow flexion concentric and eccentric isokinetic force production in college aged untrained females.

\section{Study Design}

Randomized Trial

\section{Methods}

Twenty healthy females performed pre-and-post isokinetic (60 degrees/second) concentric/eccentric testing of the elbow flexors, shoulder external rotators, and hip abductors. Participants were randomly assigned to a four-week independent low repetitions/heavy resistance strengthening program performed with either elastic bands or isotonic exercises.

\section{Results}

A significant $(p<0.05)$ effect of time was found for eccentric elbow flexor and concentric and eccentric hip abduction force production in the elastic band group with post-test values greater than pre-test values. A significant $(p<0.05)$ effect of time was found for elbow flexor concentric and eccentric force production in the isotonic group with post-test values greater then pre-test values. No significant $(p>0.05)$ effect of time was found for shoulder external rotator concentric and eccentric forces for both groups, the isotonic group's hip abduction concentric and eccentric force production and elastic band group's elbow flexion concentric force production. No significant effect of intervention ( $p$

\footnotetext{
Corresponding Author: Eric Folkins, PT, DPT University of the Sciences 600 S. 43rd Street Philadelphia, PA 19104 Phone: (215) 596-7086, Fax: (215) 895-3121 e.folkins@usciences.edu
} 
$>0.05$ ) on concentric or eccentric elbow flexors, shoulder external rotators, or hip abductors force production was found, with pre-test and post-test values being similar between groups.

\section{Conclusion}

Health care practitioners and coaches can consider the prescription of a heavy resistance training program with elastic bands or isotonic exercises for an independent exercise program and expect similar concentric and eccentric muscle force changes.

\section{Level of Evidence}

Level $2 b$

\section{INTRODUCTION}

The benefits of resistance training as part of a general fitness program and to improve health is well established and is recommended by the American College of Sports Medicine (ACSM). ${ }^{1}$ Improved muscular strength lowers cardiovascular disease, decreases risk of acquiring physical functional limitations, and improves bone mass and composition. Concentric (muscle shortening), eccentric (muscle lengthening) and isometric (no change in muscle length) muscle contractions are various ways to measure strength. ${ }^{2}$ Eccentric, concentric, and isometric strength capabilities are all important for performing well in sport activities, injury prevention, and affect rehabilitation at the knee, hip and elbow. ${ }^{3-9}$

Health care professionals, such as physical therapists and personal trainers, commonly prescribe strengthening with elastic bands and/or weights to improve muscular strength, health, and for injury prevention and rehabilitation. Weights provide a constant external load and therefore are considered an isotonic form of strengthening exercise. $^{2}$ Elastic bands, in contrast, provide linear variable resistance; meaning as range of motion increases and the band becomes more taut, resistance increases. Elastic bands have the benefit of being highly portable and are frequently used for independent exercise programs. Knowing which strengthening method (band vs. weights) may be superior for affecting eccentric, concentric and isometric strength is important for optimal outcomes.

Both isotonic and elastic band strengthening appear to result in similar concentric and isometric upper extremity and lower extremity strength gains. ${ }^{10-13}$ Prior research on the effects of strengthening comparing elastic bands to isotonic exercises has utilized males, adolescents and athletic college aged females. ${ }^{10,11,13-17}$ Previous research indicates significant increases in shoulder eccentric force using elastic bands and the combination of elastic bands with isotonic exercises compared to controls with no strengthening. ${ }^{14,15,17}$ However, research has not compared the effect on eccentric strength solely with the use of elastic bands compared to isotonic strengthening methods. Additionally, there is no research comparing elastic bands to isotonic strengthening in sedentary college aged females. Health care professionals would benefit from knowing if untrained healthy females have similar outcomes as males and athletic females, as well as comparing isotonic exercise to solely elastic band exercise strengthening outcomes. Gaining this information will provide healthcare professionals guidance regarding which method of strengthening to pre- scribe for each patient populations.

High load, low repetition or low-moderate load, high repetition exercise are two different parameters to improve muscular performance. ${ }^{18}$ ACSM considers three or more sets of four to six repetitions at $85 \%$ or greater of a one repetition maximum a high load, low repetition program intended to target improving strength. A low-moderate load, high repetition routine entails two or more sets of greater than six repetitions at less than $85 \%$ of one repetition maximum (1RM) intended to target hypertrophy and muscular endurance development. Males, adolescents, and trained females demonstrated similar isometric and concentric strength gains with either isotonic or variable resistance strengthening that utilized hypertrophy and muscular endurance strengthening parameters of low-moderate load, high repetition (> eight repetitions). ${ }^{10-14,17,19}$ Prior research has not investigated whether similar concentric and eccentric strength outcomes can be achieved with a high load, low repetition elastic band versus a high load, low repetition isotonic resistance program.

Short term strength gains are important because health care professionals such as physical therapists are often expected to demonstrate improvement in four to six weeks for reimbursement and continuation of care. The ACSM recommends initial use of low-moderate load, high repetition for untrained persons to increase endurance and learn proper form. ${ }^{18}$ However, untrained lifters demonstrated a significant increase in concentric strength with a high load, low repetition isotonic exercise routine compared to low-moderate load, high repetition following eight-weeks of lifting. ${ }^{20}$ Therefore, if the goal of an exercise program is to achieve the greatest short-term concentric and eccentric strength gains, and a client demonstrates proper form, a high load, low repetition program may be indicated. Knowledge of strength outcomes utilizing high load, low repetition program with elastic bands compared to isotonic exercises would be valuable for health care professionals to understand strength outcomes that may occur over a fourweek period.

The purpose of this research was to examine the effects of a four-week isotonic low repetitions/heavy resistance strengthening program compared to a low repetitions/ heavy resistance elastic band strengthening program on shoulder external rotation (ER), hip abduction and elbow flexion concentric and eccentric isokinetic force production in college aged untrained females.

The null hypothesis was that there would be no difference in concentric or eccentric muscle force changes found due to isotonic strengthening as compared to elastic band 
strengthening after a four-week training program.

\section{METHODS}

An a priori power analysis determined a sample size of twenty (10 in each group) based on a $5 \%$ margin of error with a 95\% confidence interval using variance determination calculated from previous studies. ${ }^{15,21}$ Twenty-four healthy females age 20-30 were recruited through word of mouth, personal contact and flyers between February and April of 2015 based on an expected 15\% drop-out rate. Researchers terminated recruitment following enrollment of 24 qualified participants. Inclusion criteria included healthy college aged females. Exclusion criteria included a current injury, current participation in a regular strength-training program or no access to a gym with weights.

The University of the Sciences Institutional Review Board approved this study prior to enrollment of participants (Protocol: 639927-4). Participants gave written informed consent prior to participation. The study was not a registered clinical trial.

\section{STUDY DESIGN}

The study was a randomized controlled trial of healthy females. Researchers blinded testers to group assignment for both pre-and post-testing. Participants completed identical pre- and post-test strength testing on the Baltimore Therapeutic Equipment (BTE) Primus RS at University of the Sciences to record force and determine correct resistance for isotonic or elastic training. Post testing occurred two to seven days following the last exercise session, which occurred over four weeks. Participants performed concentric and eccentric isokinetic testing at 60 degrees/second of the shoulder external rotators, elbow flexors, and hip abductors. The testing velocity of 60 degrees/second was previously reported to be a good representation of both concentric and eccentric force production. ${ }^{8}$ Testing parameters followed instructions as described in the BTE manual (Figure 1). ${ }^{22}$ Participant testing position for elbow flexion was in standing, feet shoulder width apart, humerus adducted to side, neutral shoulder rotation with forearm supinated. Testing position for shoulder ER was in standing, feet flat on the floor, shoulder abducted 45 degrees, elbow flexed 45 degrees and forearm in neutral position. Testing position for hip abduction was in side lying on contralateral side of hip being tested, pad placed immediately proximal to knee and hip in neutral flexion/extension. Researchers did not allow participants to use any substitution patterns during testing. All participants completed the testing protocol on the PrimusRS for the right elbow flexors, shoulder external rotators, and hip abductors through their full active range of motion.

The PrimusRS has previously demonstrated excellent test-retest reliability $\left[\mathrm{ICC}_{2,1}=0.99\right.$ (95\% CI 0.96-0.99)] for isokinetic concentric elbow flexion peak torque at 60 degrees/second. ${ }^{23}$ The same study reported excellent testretest reliability with a range of $\mathrm{ICC}_{2,1}$ values between 0.95-0.98 for concentric isokinetic testing at 60 degrees/ second for elbow extension, knee flexion and knee extension. Additional studies have reported excellent (ICC range

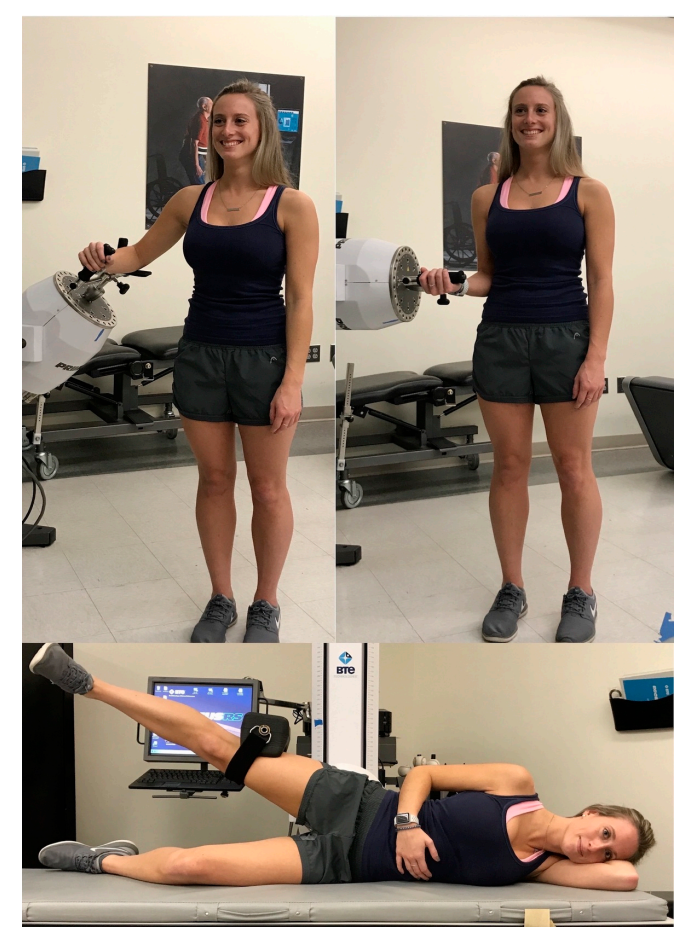

Figure 1: Isokinetic test position for shoulder external rotation, elbow flexion and hip abduction. Concentric and eccentric testing at 60 degrees per second through participants full ROM.

0.844- 0.99) test-retest reliability for concentric power of the ankle, hip force, isotonic functional tasks and static isotonic upper limb strength testing. ${ }^{24-26}$ The factory calibrated the PrimusRS prior to delivery and researchers calibrated the PrimusRS prior to each testing session to ensure accurate measurment. ${ }^{22}$

Participants performed a five-minute warm-up on a stationary bicycle prior to a warm-up of three submaximal concentric/eccentric (at $50 \%$ perceived effort) repetitions and one maximal repetition to familiarize participants with the movement. They then received a one-minute rest followed by testing of five maximal reciprocal repetitions on the right side. Researchers documented the average maximal concentric and eccentric peak force of the five repetitions. The average of the five test contractions was previously utilized for isokinetic testing of the shoulder. ${ }^{14}$ Individuals received a five-minute rest between testing motions. Following testing an independent researcher, blinded to test results, randomly assigned participants to either a strength training program with Theraband ${ }^{\circledR}$ elastic band (EB) or isotonic exercises (IS) using Microsoft Excel (2013).

Investigators converted average maximal peak force $(\mathrm{N})$ of the five concentric contractions to kilograms. The independent exercise prescription included three sets (oneminute rest between sets), of four to six repetitions, performed three times per week (minimum 48 hours rest between sessions) for four weeks. Final data inclusion required participants complete eight sessions over four weeks, as previous studies demonstrated strength and functional improvement in as little as four weeks in healthy populations and three to four weeks in persons with lumbar 
and shoulder pathology $14,27,28$ A National Strength and Conditioning Association Certified Strength and Conditioning Specialist supervised instruction of subjects in their independent exercise training sessions. Participants returned one week after initial training to ensure they were performing the exercises correctly.

The IS group attended the university gym and independently completed dumbbell elbow flexion (bicep curls) and dumbbell side lying shoulder ER with shoulder at adducted to side (Figure 2). Researchers prescribed the appropriate weight to achieve $85 \%$ of the calculated kilograms of maximum concentric peak isokinetic force that was produced during testing. The IS group performed hip abduction strengthening on the Life Fitness ${ }^{\mathrm{TM}}$ Optima Series Hip Abductor/Adductor secondary to the use of cuff weights did not achieve required resistance (Figure 2). The EB group performed standing elbow flexion (bicep curl), standing shoulder ER with shoulder adducted to side and hip abduction in side-lying with bands around knees (Figure 3). Researchers prescribed the appropriate color of Theraband ${ }^{\circledR}$ Resistance Bands (https://www.theraband.com) and percent stretch to achieve $85 \%$ of maximum concentric peak torque peak isokinetic force that was produced during testing as previously published. ${ }^{29}$ Participants performed four to six repetitions at a rate of one repetition per six seconds (three seconds concentric and three seconds eccentric contraction) in a controlled motion. Participants kept a self-reported log of the days, sets, repetitions and resistance of exercises completed. Participants performed the exercises at the same prescribed resistance during the four-week training period.

\section{STATISTICAL ANALYSIS}

Statistical analysis was conducted with SPSS (IBM SPSS Statistics 25, Armonk, NY, USA). Descriptive statistics were calculated. Independent $t$-tests were performed to compare any differences in age and compliance between the two groups. Preliminary data screening procedures were performed to assess the basic assumptions of ANOVA. Data were normally distributed except for elbow flexion post concentric results. A $2 \times 2$ mixed factorial ANOVA assessed whether differences existed in concentric and eccentric isokinetic forces in response to an EB and IS strengthening program. Homogeneity of the variance assumption was assessed with Levene's test and demonstrated a significant $\mathrm{p}$ value for elbow concentric pre-and post-testing $(p=0.001)$ and hip abduction eccentric pre-testing $(\mathrm{p}=0.021)$. Levene's test for all other variables were non-significant ( $p>0.05$ ). The Mann-Whitney U non-parametric statistical analysis was used for elbow flexion concentric and hip abduction eccentric results.

\section{RESULTS}

There was no significant difference (t $(1.85)=18, \mathrm{p}=0.08$ ) in age between the isotonic $(\mathrm{M}=23.90, \mathrm{SD}=2.23 \mathrm{~N}=10)$ and elastic band $(\mathrm{M}=22.30, \mathrm{SD}=1.57, \mathrm{~N}=10)$ groups. Two of the initial 12 subjects recruited in each of the IS group and EB groups did not complete the required minimum eight exercise sessions over four weeks and therefore twenty partic-

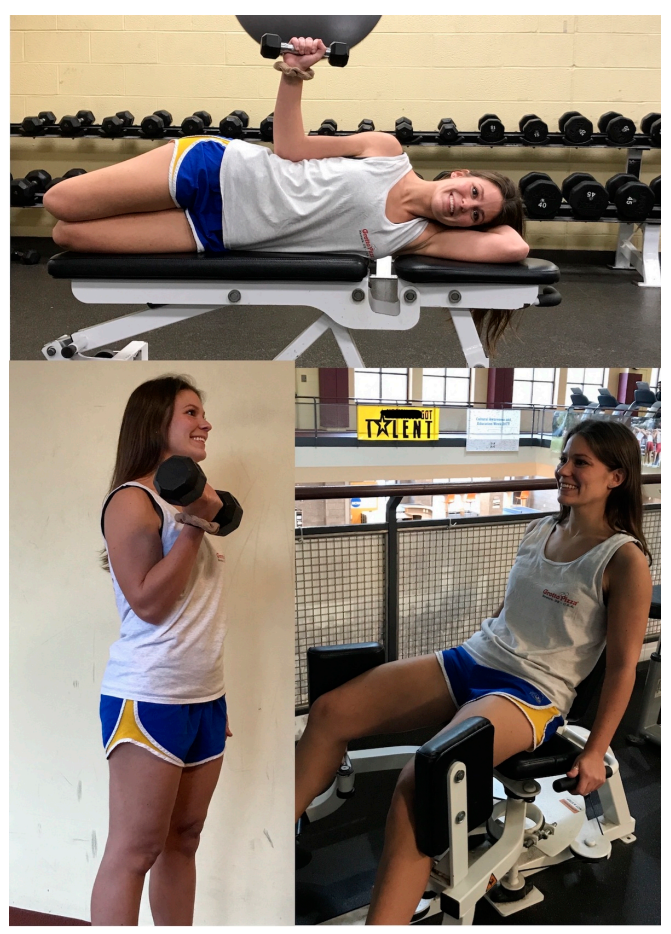

Figure 2: Isotonic strengthening exercises for shoulder external rotation, elbow flexion and hip abduction. Participants performed each exercise through their full available range of motion.

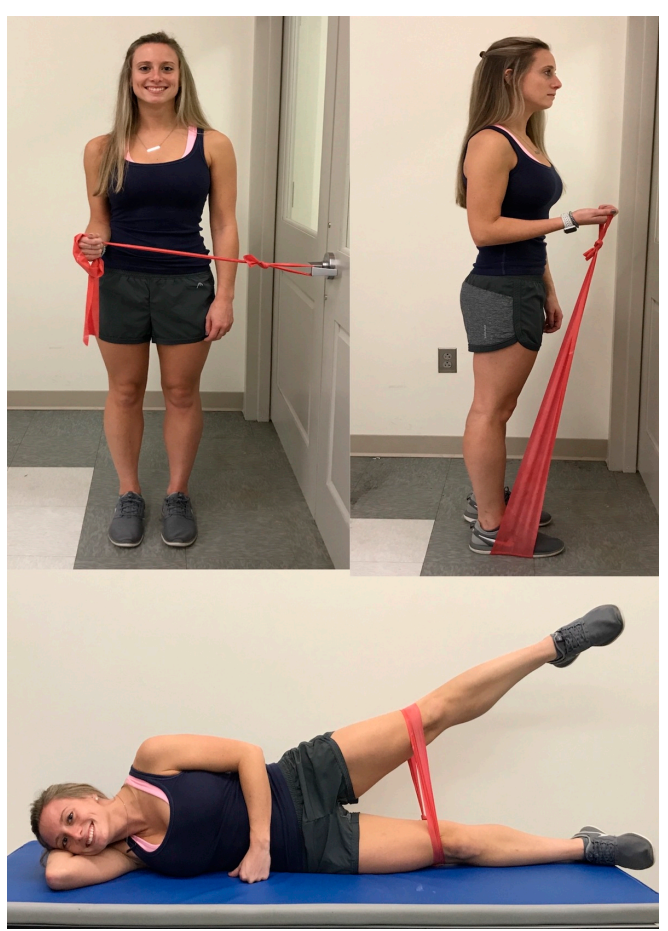

Figure 3: Elastic strengthening exercises for external rotation, elbow flexion and hip abduction. Participants performed each exercise through their full available range of motion. Elastic band resistance set at $50 \%$ of available range of motion. 
Table 1: Mann Whitney $U$ test for pre-and post-testing between groups for concentric elbow flexion concentric and eccentric hip abduction force production.

\begin{tabular}{|c|c|c|c|c|c|c|c|}
\hline & Testing & $\begin{array}{c}\text { Isotonic } \\
(n=10)\end{array}$ & $\begin{array}{l}\text { Elastic band } \\
\quad(n=10)\end{array}$ & $\mathbf{U}$ & Z & $\mathrm{p}$-value & $\eta^{2}$ \\
\hline & & Mrank & Mrank & & & & \\
\hline \multirow[t]{2}{*}{ Elbow flexion concentric (N) } & Pre-testing & 8.80 & 12.20 & 33.00 & -1.285 & .199 & \\
\hline & Post-testing & 11.10 & 9.90 & 44.00 & -.454 & .650 & 0.01 \\
\hline \multirow[t]{2}{*}{ Hip abduction eccentric (N) } & Pre-testing & 9.25 & 11.75 & 37.50 & -9.45 & .345 & \\
\hline & Post-testing & 8.85 & 12.15 & 33.50 & -1.25 & .650 & 0.08 \\
\hline
\end{tabular}

Table 2: Pre-testing and Post-testing descriptive data $(\mathrm{N})$ and percent change within each group between testing sessions.

\begin{tabular}{|c|c|c|c|c|c|c|}
\hline & Group & $\begin{array}{l}\text { Pre-Testing } \\
(n=10)\end{array}$ & $\begin{array}{l}\text { Post-testing } \\
\quad(n=10)\end{array}$ & $95 \% \mathrm{Cl}$ & $\begin{array}{c}\mathrm{p}- \\
\text { value }\end{array}$ & $\begin{array}{c}\% \\
\text { Change }\end{array}$ \\
\hline & & Mean (SD) & Mean (SD) & & & \\
\hline \multirow[t]{2}{*}{ Elbow flex Conc } & Isotonic & $70.5(11.55)$ & $91.28(20.75)$ & $(-35.78,-6.41)$ & $\dagger$ & 30 \\
\hline & $\begin{array}{l}\text { Elastic } \\
\text { band }\end{array}$ & $88.65(25.05)$ & $100.12(46.35)$ & $(-37.99,3.30)$ & $\dagger$ & 13 \\
\hline \multirow[t]{2}{*}{ Elbow flex Ecc } & Isotonic & $99.28(22.65)$ & $130.32(33.35)$ & $(-57.82,-4.24)$ & $.03^{*}$ & 31 \\
\hline & $\begin{array}{l}\text { Elastic } \\
\text { band }\end{array}$ & $112.86(41.72)$ & $140.48(70.75)$ & $(-61.19,-1.77)$ & $.04^{*}$ & 25 \\
\hline \multirow[t]{2}{*}{$\begin{array}{l}\text { Shoulder ER } \\
\text { Conc }\end{array}$} & Isotonic & $54.06(11.19)$ & 61.84(17.75) & $(-19.91,4.35)$ & .18 & 14 \\
\hline & $\begin{array}{l}\text { Elastic } \\
\text { band }\end{array}$ & $57.29(19.15)$ & $68.82(14.81)$ & $(-25.58,1.73)$ & .08 & 20 \\
\hline \multirow[t]{2}{*}{ Shoulder ER Ecc } & Isotonic & 64.21(12.99) & 69.81(14.93) & $(-19.3,8.1)$ & .38 & 9 \\
\hline & $\begin{array}{l}\text { Elastic } \\
\text { band }\end{array}$ & 69.19(20.22) & 75.50(14.72 & $(-24.61,9.18)$ & .32 & 8 \\
\hline \multirow[t]{2}{*}{ Hip Abd Conc } & Isotonic & $229.87(66.51)$ & $253.24(79.29)$ & $(-59.93,13.23)$ & .18 & 10 \\
\hline & $\begin{array}{l}\text { Elastic } \\
\text { band }\end{array}$ & 259.92(113.52) & $296.87(90.81)$ & $(-69.89,-3.6)$ & $.03^{*}$ & 14 \\
\hline \multirow[t]{2}{*}{ Hip Abd Ecc } & Isotonic & $259.59(48.79)$ & $277.90(69.94)$ & $(-53.52,16.89)$ & $\dagger$ & 7 \\
\hline & $\begin{array}{l}\text { Elastic } \\
\text { band }\end{array}$ & 299.01(93.53) & $332.84(70.53)$ & $\begin{array}{l}(-63.15 \\
-13.82)\end{array}$ & $\dagger$ & 11 \\
\hline $\begin{array}{l}\mathrm{N}=\text { Newtons; flex } \\
{ }^{*} \text { Within group sig } \\
\text { Table } 3\end{array}$ & $\begin{array}{l}\text { ion; } E R=e \\
\text { int differe }\end{array}$ & $\begin{array}{l}\text { rotation; } A B D= \\
05) \text {; between pre }\end{array}$ & $\begin{array}{l}\text { on; Ecc = Eccentri } \\
\text { st-testing, †- No }\end{array}$ & $\begin{array}{l}=\text { concentric } \\
\text { eetric statistics }\end{array}$ & ed in & \\
\hline
\end{tabular}

ipants (10 per group) were included in final data analysis. None of the participants reported an adverse event.

There was no significant difference $(t(0.16)=18, p=0.87$ ) in compliance (sessions completed) between the IS $(\mathrm{M}=11.30, \mathrm{SD}=0.95)$ and $\mathrm{EB}(\mathrm{M}=11.20, \mathrm{SD}=1.69)$ groups. There was no significant difference in pre-test and post-test values for concentric elbow flexor $(p=0.199$ and $p=0.650$ respectively) and eccentric hip abductor forces ( $\mathrm{p}=0.35$ and $\mathrm{p}=0.65$ respectively) between the two groups. (Table 1 ).

The results showed no significant main effect of intervention $\left(F(1,18)=.406 \mathrm{p}=0.532, \eta^{2}=.022\right)$ for eccentric elbow flexors, $\left(\mathrm{F}(1,18)=.715, \mathrm{p}=0.409, \eta^{2}=.038\right)$ concentric shoulder external rotators, $\left(\mathrm{F}(1,18)=.946 \mathrm{p}=0.344, \eta^{2}=.05\right)$ eccentric shoulder external rotators, and $(F(1,18)=.913$ $\mathrm{p}=0.352, \eta^{2}=.048$ ) concentric hip abductor force production with pre-test and post-test values being similar between groups (Figure 4). Percent change in force within each group ranged from 7-30\% (Table 2).

The results demonstrated a significant main effect of time for both groups between pre- and post-test $(\mathrm{F}(1,18)$ $\left.=11.94, \mathrm{p}=0.003, \eta^{2}=.399\right)$ on eccentric elbow flexors, $(\mathrm{F}$ $\left.(1,18)=6.55, \mathrm{p}=0.02, \eta^{2}=.267\right)$, concentric shoulder external rotators $\left(\mathrm{F}(1,18)=8.52, \mathrm{p}=0.009, \eta^{2}=.321\right)$, and concentric hip abductor forces with post-intervention force greater than pre-intervention force (Table 2 ). There was no significant main effect for change in force between pre-and posttest $\left(\mathrm{F}(1,18)=1.74, \mathrm{p}=0.204, \eta^{2}=.088\right)$ for eccentric ER. Means and SD are located in Figure 4 and Table 2. The EB 
Table 3: Wilcoxon-signed rank results for comparing pre-and post-testing forces within each group for elbow flexion concentric and hip abduction eccentric

\begin{tabular}{|c|c|c|c|c|c|c|}
\hline & Group & $\begin{array}{l}\text { Pre-Testing } \\
(\mathrm{n}=10)\end{array}$ & $\begin{array}{l}\text { Post-testing } \\
(n=10)\end{array}$ & Z & $\mathrm{p}$-value & $\eta^{2}$ \\
\hline & & Median & Median & & & \\
\hline \multirow[t]{2}{*}{ Elbow flexion concentric (N) } & Isotonic & 70.5 & 91.28 & -2.50 & $.013^{*}$ & 0.33 \\
\hline & Elastic band & 83.79 & 73.15 & -866 & .386 & 0.04 \\
\hline \multirow[t]{2}{*}{ Hip abduction eccentric (N) } & Isotonic & 256.28 & 298.10 & -866 & .386 & 0.04 \\
\hline & Elastic band & 314.93 & 338.60 & -2.40 & $.017^{*}$ & 0.30 \\
\hline
\end{tabular}

group had a significant increase in concentric hip abductor force $(p=0.03)$ whereas the IS group demonstrated no significant increase $(p>0.05)$ (Table 2).

Concentric elbow flexor and eccentric hip abductor forces did not have normal distribution. Therefore, non-parametric statistics (Wilcoxon signed rank) compared pre-test and post-test values within each group for these outcomes. The IS group had a significant ( $\mathrm{p}=0.013$ ) increase in concentric elbow flexor force but there was not a significant $(p=0.386)$ change in eccentric hip abduction force between pre- and post testing (Table 3). The EB group had a significant $(\mathrm{p}=0.017)$ increase in eccentric hip abductor force but not a significant $(p=0.386)$ change in concentric elbow flexor force between pre- and post-testing (Table 3).

\section{DISCUSSION}

\section{ELASTIC TUBING VS. ISOTONIC EXERCISE}

The present study demonstrated that a four-week heavy resistance (85\% 1RM) program with isotonic exercises was comparable to elastic band exercises for concentric and eccentric force outcomes in healthy untrained females for hip abduction, elbow flexion and shoulder ER. The isokinetic concentric force production in untrained females following either an IS or EB program is in agreement with a previous study on isotonic strength outcomes of untrained middle aged men with cardiovascular disease following either an IS or EB program. ${ }^{13}$ Turban et al. reported no difference in 1RM isotonic concentric strength (on a weight machine) for elbow and knee extension following five weeks of resistance training using elastic bands or a weight machine. They reported concentric strength increases between $13 \%$ and $24 \%$ for knee and elbow extensor. The untrained female participants' in the current study demonstrated similar isokinetic concentric force increases between $10 \%$ and $30 \%$ for elbow flexors, external rotators and hip abductors. The large $30 \%$ increase in the IS group for the elbow flexors may be due to one participant having a low initial bicep force, therefore decreasing the pre-testing group mean force score resulting in a larger increase in post-testing force. Nonparametric testing accounted for data not being normally distributed and resulted in no significant difference in posttest scores for the elbow flexors. This study is the first to demonstrate comparable eccentric force changes with IS and EB exercises. The eccentric force changes were slightly

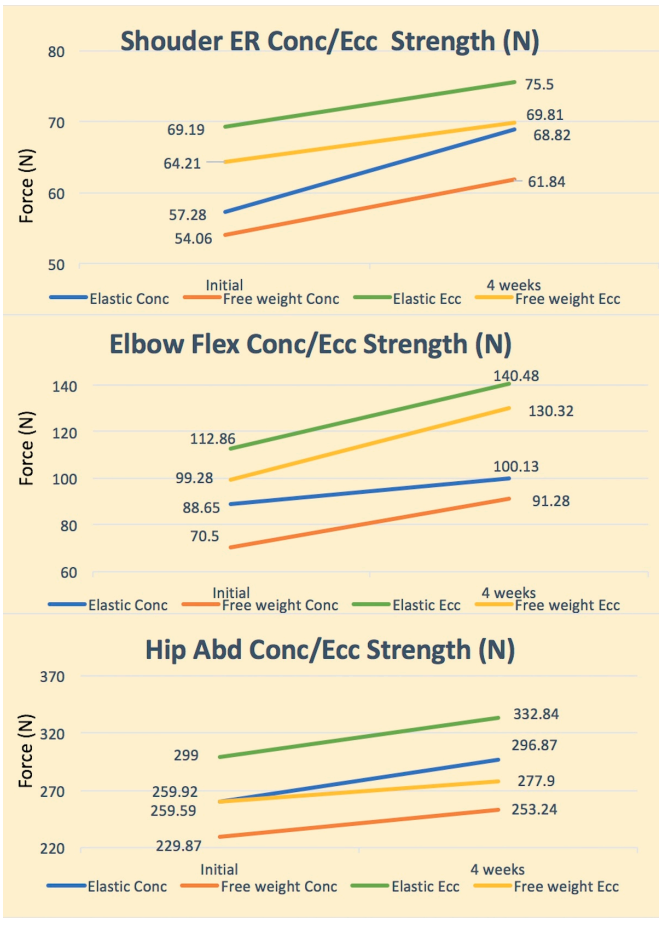

Figure 4: Mean shoulder external rotation, elbow flexion and hip abduction concentric/eccentric force (N) pre-and post-test. Elastic - elastic band group; Free weight - isotonic group; Conc - concentric; Ecc eccentric; No significant difference between groups pretest and post-test.

less (7\%-14\%) than concentric force changes. The current study adds additional evidence to indicate that isotonic strengthening is comparable to elastic band strengthening for both concentric and eccentric force in a healthy female population with no previous strength training experience.

Colado et al. reported equivalent functional isometric strength for vertical rowing, squat and back extension increases in young (mean 21.79 years) physically fit females that completed a resistance program with elastic tubing or with weight machines/free weights. ${ }^{10}$ Their functional isometric results were similar to the current isokinetic force results in an untrained population of the same age and sex. The current four week results are also in agreement with the results by Lima et al. following a 12-week exercise program 
in middle aged males and females (age range 54-62). ${ }^{11}$ They reported similar positive isometric strength gains between IS and EB training at six and 12 weeks and also comparable functional exercise capacity. ${ }^{11}$ These previous studies comparing elastic tubing to isotonic exercises utilized multijoint and functional task measurements of strength. ${ }^{11,12}$ Therefore, it remains unclear if different muscles or groups of muscles respond similarly to elastic bands and isotonic strengthening.

The use of both upper extremity and lower extremity isolated muscle group testing positions in this study demonstrated that the hip abductors (gluteus medius), shoulder external rotators (teres minor, infraspinatus), and elbow flexors (biceps) responded similarly to elastic band and isotonic strengthening programs. Strength increases in the first four-weeks are predominately from neural adaptations such as improved neural recruitment, central nervous activation, improved motor unit firing and inhibitory mechanisms. ${ }^{2}$ The comparable outcomes in this study may result in similar neural adaptations regardless if IS or EB resistances is utilized. Therefore, not surprisingly, specific upper and lower extremity muscles demonstrate similar strength changes. The isolated muscle group strength increase in four weeks is important information for rehabilitation professionals. Rehabilitation professional target individual muscle groups early in injury recovery and progress to functional activities. Campos et al. demonstrated greater concentric strength gains in eight weeks with a low repetition/ high load resistance program compared to a high repetition/ low load resistance program. ${ }^{20}$ The increase in both concentric and eccentric force in four weeks demonstrated in the current study and results from the previous study provide evidence that both IS and EB resistance utilizing low repetitions/high load resistance can be effectively utilized as an alternative for patients that may not tolerate high repetitions due to pain. ${ }^{20}$ Strength of these specific muscle groups are all important for performing sport activities, injury prevention and rehabilitation at the knee, hip and elbow.3,5-7,9 Health care professionals can utilize either strength training method to similarly increase functional, isometric and isolated concentric and eccentric isokinetic muscle group force.

\section{PARAMETERS}

Although previous studies used higher repetitions than the current study, the current study demonstrated similar increases in concentric shoulder ER $(14 \%, 20 \%)$ force and less eccentric shoulder ER (8\%, 9\%) force at four weeks compared to five and 12 week programs. ${ }^{11-14,17}$ Two studies of isokinetic shoulder strength changes compared elastic tubing programs to elastic tubing combined with free weights and to controls. ${ }^{11,13}$ The strengthening protocol by Turban et al. included four sets of 12 contractions for five weeks at a perceived exertion of $13-15$ on the 6-20 Borg scale. ${ }^{13}$ Lima et al. in contrast had a longer training program of 12 -weeks and implemented a progressive design with $2 \times 15$

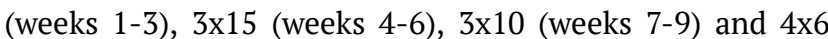
(weeks 10-12). ${ }^{11}$ Resistance in the study by Lima et al. increased if a participant could perform more than two of the prescribed repetitions at a given resistance. Two different studies reported a $17.0 \%$ increase in peak torque and no significant increase respectively in collegiate tennis players following four to five weeks of 15-20 repetitions of band exercises 3-4x/week. ${ }^{14,17}$

Similar concentric and eccentric strength results are achieved regardless of mode of resistance (isotonic or elastic band), intensity (percentage of maximal force or perceived exertion) or number of repetitions performed between four and 12 weeks.

Key components of resistance training are prescription of appropriate resistance and corresponding repetitions to induce a moderate to hard effort irrespective of mode of resistance. There are various proposed methods to determine the appropriate amount of resistance when training with elastic bands/tubing. Isokinetic force results, used to determine resistance, as utilized in this study, reflect the use of the gold standard of force measurement. However, an isokinetic device is costly and not readily available to all healthcare professionals. Resistance correlating to isotonic resistance of Theraband ${ }^{\circledR}$ elastic bands, tubing and CLX ${ }^{\mathrm{TM}}$ bands has been previously reported for each color. ${ }^{29,30}$ Clinicians can use these or other documented values of variable resistance to determine a $1 \mathrm{RM}$ and then choose appropriate training loads. Calculation of a $1 \mathrm{RM}$ from a $50 \%$ perceived effort maximum repetitions test using the CLX ${ }^{\mathrm{TM}}$ bands found almost perfect agreement $\left(\mathrm{R}^{2}=0.98\right)$ with a $1 \mathrm{RM}$ test. ${ }^{31}$ A benefit of a $50 \%$ maximum repetition test is utilization with injured or untrained individuals to reduce risk of injury that may come from a $1 \mathrm{RM}$ test. Michelitti et al. also calculated estimated intensity of workload based on number of repetitions performed with the CLX ${ }^{\mathrm{TM}}$ bands for training purposes. ${ }^{31}$ The Borg scale from 6-20 and the OMNI-Resistance scale (0 "Extremely easy" - 10 Extremely hard) demonstrated a significant positive correlation with force applied during variable resistance exercises. ${ }^{13,32}$ These rate of perceived exertion methods are easy to administer and available to anyone, but less accurate than previously described methods. A health care professional can utilize one of these reliable proven methods of exercise prescription with elastic bands to achieve comparable strength benefits to isotonic resistance training.

Limitations of the study should be considered when comparing current results to previous research and alternative populations. This study was limited to inclusion criteria of untrained females between 20-30 years of age. A health care practitioner should be cautious in outcome expectations with males, different age groups and active persons, as these populations have not been fully studied. Larger sample sizes (> 10 in each group) and longer training studies of eight or more weeks may concur with the current findings or have different results. The short duration (four weeks) of the study may not have allowed adequate time for muscle hypertrophy to occur, however this parameter was not measured. A study greater than eight weeks in duration is recommended to determine if long term comparison of strength gains between modes of resistance is a result of hypertrophy or solely neuromuscular changes. ${ }^{18}$ There may have been differences in participants' intensity and compliance due to reliance on participants' self-reports. Attempts to control for intensity and compliance were made by researchers initially training subjects and performing a 
one-week follow-up to ensure correct intensity and exercise form. Additionally, researchers may add a rate of perceived exertion scale to increase the likelihood participants are exercising at the correct intensity. The current study duration, untrained population and independent exercise program are common parameters encountered by healthcare practitioners and therefore clinically relevant.

\section{CONCLUSION}

The results of the current study indicate comparable isokinetic concentric and eccentric force outcomes in untrained females following an independent four-week low repetition/ high load IS or EB resistance program. Practitioners can confidently prescribe and expect positive concentric and eccentric strength changes with either mode of resistance based on equipment availability and a person's comfort level. The portability of elastic bands allows athletes and clients to continue strength training programs during travel and vacations with continued improvement. The use of EBs and weights can be utilized in an independent home exercise program to increase strength as long as adequate resistance, repetitions, intensity and instruction are utilized.

\section{CONFLICT OF INTEREST}

The Theraband Academy supplied Theraband ${ }^{\circledR}$ resistance bands for this research, however, no authors have a financial interest.

Submitted: June 09, 2020 CDT, Accepted: January 23, 2021 CDT 


\section{REFERENCES}

1. Pescatello LS, American College of Sports Medicine. ACSM's Guidelines for Exercise Testing and Prescription. 9th ed. Philadelphia: Wolters Kluwer/ Lippincott Williams \& Wilkins Health; 2014.

2. McCardle W, Katch F, Katch V. Exercise Physiology: Nutrition, Energy, and Human Performance. 8th ed. Baltimore, MD: Wolters Kluwer; 2015.

3. McPoil TG, Martin RL, Cornwall MW, Wukich DK, Irrgang JJ, Godges JJ. Heel pain--plantar fasciitis: clinical practice guildelines linked to the international classification of function, disability, and health from the orthopaedic section of the American Physical Therapy Association. J Orthop Sports Phys Ther. 2008;38(4):A1-A18. doi:10.2519/jospt.2008.030 $\underline{2}$

4. Blanpied PR, Gross AR, Elliott JM, et al. Neck pain: Revision 2017. J Orthop Sports Phys Ther. 2017;47(7):A1-A83. doi:10.2519/jospt.2017.0302

5. Cibulka MT, White DM, Woehrle J, et al. Hip pain and mobility deficits--hip osteoarthritis: clinical practice guidelines linked to the international classification of functioning, disability, and health from the orthopaedic section of the American Physical Therapy Association. J Orthop Sports Phys Ther. 2009;39(4):A1-25. doi:10.2519/jospt.2009.0301

6. Delitto A, George SZ, Van Dillen LR, et al. Low back pain. J Orthop Sports Phys Ther. 2012;42(4):A1-57. do i:10.2519/jospt.2012.0301

7. Logerstedt DS, Scalzitti DA, Bennell KL, et al. Knee pain and mobility impairments: meniscal and articular cartilage lesions revision 2018. J Orthop Sports Phys Ther. 2018;48(2):A1-A50. doi:10.2519/jos pt.2018.0301

8. Boling MC, Padua DA, Alexander Creighton R. Concentric and eccentric torque of the hip musculature in individuals with and without patellofemoral pain. J Athl Train. 2009;44(1):7-13. do i:10.4085/1062-6050-44.1.7

9. Chaconas EJ, Kolber MJ, Hanney WJ, Daugherty ML, Wilson SH, Sheets C. Shoulder external rotator eccentric training versus general shoulder exercise for subacromial pain syndrome: A randomized controlled trial. Int J Sports Phys Ther. 2017;12(7):1121-1133.

10. Colado JC, Garcia-Masso X, Pellicer M, Alakhdar Y, Benavent J, Cabeza-Ruiz R. A comparison of elastic tubing and isotonic resistance exercises. Int J Sports Med. 2010;31(11):810-817. doi:10.1055/s-0030-12628 $\underline{08}$
11. Lima FF, Camillo CA, Gobbo LA, et al. Resistance training using low cost elastic tubing is equally effective to conventional weight machines in middleaged to older healthy adults: A quasi-randomized controlled clinical trial. J Sports Sci Med. 2018;17(1):153-160.

12. Mangione KK, Miller AH, Naughton IV. Cochrane review: Improving physical function and performance with progressive resistance strength training in older adults. Phys Ther. 2010;90(12):1711-1715. doi:10.252 2/ptj.20100270

13. Turban C, Culas C, Deley G. Effects of a short-term resistance program using elastic bands or weight machines in cardiac rehabilitation. Sci Sports. 2014;29:143-149.

14. Niederbracht Y, Shim AL, Sloniger MA, Paternostro-Bayles M, Short TH. Effects of a shoulder injury prevention strength training program on eccentric external rotator muscle strength and glenohumeral joint imbalance in female overhead activity athletes. J Strength Cond Res. 2008;22(1):140-145. doi:10.1519//SC.0b013e31815f56 $\underline{34}$

15. Page PA, Lamberth J, Abadie B, Boling R, Collins $\mathrm{R}$, Linton R. Posterior rotator cuff strengthening using theraband in a functional diagonal pattern in collegiate baseball pitchers. J Athl Train. 1993;28(4):346-354.

16. Sundstrup E, Jakobsen MD, Andersen CH, et al. Evaluation of elastic bands for lower extremity resistance training in adults with and without musculo-skeletal pain. Scand J Med Sci Sports. 2014;24(5):e353-359. doi:10.1111/sms.12187

17. Treiber FA, Lott J, Duncan J, Slavens G, Davis H. Effects of Theraband and lightweight dumbbell training on shoulder rotation torque and serve performance in college tennis players. Am J Sports Med. 1998;26(4):510-515. doi:10.1177/036354659802 $\underline{60040601}$

18. American College of Sports M. American College of Sports Medicine position stand. Progression models in resistance training for healthy adults. Med Sci Sports Exerc. 2009;41(3):687-708. doi:10.1249/MS $\underline{\mathrm{S} .0 \mathrm{~b} 013 \mathrm{e} 3181915670}$

19. Baechle TR, Earle RW, National Strength \& Conditioning Association (U.S.). Essentials of Strength Training and Conditioning. 3rd ed. Champaign, IL: Human Kinetics; 2008. 
20. Campos GE, Luecke TJ, Wendeln HK, et al. Muscular adaptations in response to three different resistance-training regimens: specificity of repetition maximum training zones. Eur J Appl Physiol. 2002;88(1-2):50-60. doi:10.1007/s00421-002-0681-6

21. McCarrick MJ, Kemp JG. The effect of strength training and reduced training on rotator cuff musculature. Clin Biomech (Bristol, Avon). 2000;15 Suppl 1:S42-45.

22. PrimusRS Operator's Manual. Hanover, Maryland: BTE Technologies, Inc; 2015.

23. Torpel A, Becker T, Thiers A, Hamacher D, Schega L. Inter-session reliability of isokinetic strength testing in knee and elbow extension and flexion using the BTE PrimusRS. J Sport Rehabil. 2017:1-14. doi:1 0.1123/jsr.2016-0209

24. Hoglund LT, Wong AL, Rickards C. The impact of sagittal plane hip position on isometric force of hip external rotator and internal rotator muscles in healthy young adults. Int J Sports Phys Ther. 2014;9(1):58-67.

25. Kim Y, Lim JM, Yoon B. Changes in ankle range of motion and muscle strength in habitual wearers of high-heeled shoes. Foot Ankle Int. 2013;34(3):414-419. doi:10.1177/1071100712468562

26. Lee GK, Chan CC, Hui-Chan CW. Consistency of performance on the functional capacity assessment: static strength and dynamic endurance. Am J Phys Med Rehabil. 2001;80(3):189-195.
27. Jette AM, Smith K, Haley SM, Davis KD. Physical therapy episodes of care for patients with low back pain. Phys Ther. 1994;74(2):101-110. doi:10.1093/ptj/ 74.2.101

28. Kromer TO, Tautenhahn UG, de Bie RA, Staal JB, Bastiaenen $\mathrm{CH}$. Effects of physiotherapy in patients with shoulder impingement syndrome: a systematic review of the literature. J Rehabil Med.

2009;41(11):870-880. doi:10.2340/16501977-0453

29. Thera-Band: Resistance Band \& Tubing Instruction Manual.

30. Patterson RM, Stegink Jansen CW, Hogan HA, Nassif MD. Material properties of Thera-Band Tubing. Phys Ther. 2001;81(8):1437-1445.

31. Micheletti JK, Pastre CM, Machado AF, Souto LR, Lopes SI, Andersen LL. Determination of shoulde abduction strength using a submaximal elastic band test. J Perform Health Res. 2017;1(2):31-39. doi:10.250 36/iphr.2017.1.2.micheletti

32. Colado JC, Pedrosa FM, Juesas A, et al. Concurrent validation of the OMNI-Resistance Exercise Scale of perceived exertion with elastic bands in the elderly. Exp Gerontol. 2018;103:11-16. doi:10.1016/i.exger.201 $\underline{7.12 .009}$ 